\title{
Article
}

\section{Food fraud vulnerability assessment tools used in food industry}

Soon, Jan Mei, Krzyzaniak, Sally-Ann, Shuttlewood, Zoe, Smith, Madeleine and Jack, Lisa

Available at http://clok.uclan.ac.uk/26402/

Soon, Jan Mei ORCID: 0000-0003-0488-1434, Krzyzaniak, Sally-Ann, Shuttlewood, Zoe, Smith, Madeleine and Jack, Lisa (2019) Food fraud vulnerability assessment tools used in food industry. Food Control, 101 . pp. 225-232. ISSN 0956-7135

It is advisable to refer to the publisher's version if you intend to cite from the work. http://dx.doi.org/10.1016/j.foodcont.2019.03.002

For more information about UCLan's research in this area go to http://www.uclan.ac.uk/researchgroups/ and search for <name of research Group>.

For information about Research generally at UCLan please go to http://www.uclan.ac.uk/research/

All outputs in CLoK are protected by Intellectual Property Rights law, including Copyright law. Copyright, IPR and Moral Rights for the works on this site are retained by the individual authors and/or other copyright owners. Terms and conditions for use of this material are defined in the policies page.

\section{CLoK}

Central Lancashire online Knowledge www.clok.uclan.ac.uk

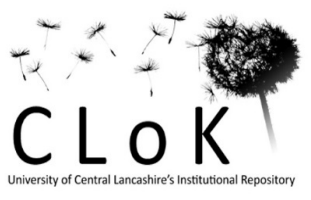




\title{
Food fraud vulnerability assessment tools used in food industry
} Soon, J. M. ${ }^{11}$, Krzyzaniak, S. C. ${ }^{2}$, Shuttlewood, Z. ${ }^{1}$, Smith, M. ${ }^{3}$ and Jack, L. ${ }^{2}$

\author{
${ }^{1}$ Faculty of Health and Wellbeing, University of Central Lancashire, Preston PR1 2HE, UK \\ ${ }^{2}$ Portsmouth Business School, University of Portsmouth, Portsmouth P01 2UP, UK \\ ${ }^{3}$ School of Chemical Engineering, University ot Birmingham, Edgbaston, Birmingham B15 2TT, UK
}

\begin{abstract}
In recent years, the issue of food fraud has become both widely discussed within the food industry and seemingly more prevalent, with incidents happening worldwide. The purpose of this study was to investigate the use of different types of anti-fraud tools within the UK food industry. The study utilised an online survey questionnaire and food manufacturing companies were invited to participate in the study via email and calls for participation through industry networks i.e. Food Integrity Intelligence Network (FIIN), the Federation of Bakers and the Food and Drink Federation. Nineteen food manufacturers returned the completed survey. Of the food businesses surveyed, most used their own in-house food fraud vulnerability assessment (FFVA) tools followed by the Campden Threat Assessment and Critical Control Point (TACCP). Campden TACCP is the evaluation of threats, identification of vulnerabilities and implementation of controls of the entire production process. The threats controlled by TACCP include economically motivated adulteration (EMA) and malicious contamination. Around one third of the companies reported being victims of food fraud. Food manufacturers were divided about the impact of conducting food fraud vulnerability assessments. Half of the food manufacturers were optimistic about the impact of FFVA whilst the rest were uncertain or negative. Positive impacts include raising awareness and ensuring integrity of food supply chain whilst negative views were associated with cost and concerns for brand reputation. The adoption and conduct of FFVA is still at its infancy and the full impact remains to be seen. However, with time and constant vigilance from the food industry, FFVA will benefit the sector and the safety and integrity of the food supply chain.
\end{abstract}

Keywords: control measures; food integrity; fraud; vulnerability assessment

\section{Highlights}

- One third of surveyed food manufacturers were victims of food fraud

- Most food manufacturers used their own in-house food fraud vulnerability assessment tools

- $47 \%$ were positive about impact of conducting food fraud vulnerability assessments

\section{Introduction}

Food fraud is a purposive act of substitution, addition, tampering or misrepresentation of food, food ingredients or food packaging and is carried out for the purpose of economic gain (Spink and Moyer,

\footnotetext{
${ }^{1}$ Corresponding author: jmsoon@uclan.ac.uk; Tel: (+44)1772 894567
} 
2011). Although food fraud detection and preventative measures have been developed and are being implemented throughout the food supply chain (SSAFE, 2018; van Ruth et al., 2017), food fraud cases are still reported globally. Recent cases include dilution of maple syrup with cheaper table sugar (EC 2018), substitution of premium fish with other species (Xiong et al., 2018), mislabelling of seafood (Pardo et al., 2018), repackaging rice with new expiry dates (Mutuko, 2018) and mixing groundnuts with stones and gravel (Food Fraud Risk Information, 2018). The agri-food industry needs to be constantly vigilant to protect the integrity of the food supply chain. The Elliot Review proposed the implementation of a national food crime framework in the United Kingdom after the 2013 horsemeat scandal (Elliott Review, 2014) leading to the introduction of the National Food Crime Unit (NFCU). In addition to international and national preventative measures, supply chains and individual food businesses must be prepared to mitigate, and where possible prevent, food fraud from occurring. Everstine (2013) highlighted the need for a holistic and systematic approach to mitigate food fraud via appropriate risk assessment techniques and use of historical data sources and/or intelligence.

Research to date has tended to focus on analytical methods to detect food fraud. A number of excellent reviews on analytical techniques on both targeted (i.e. where compound of interest is known) and non-targeted methods (e.g. screening) have been published (Abbas et al., 2018; Esteki et al., 2018; Valdes et al., 2018). The perceived increased prevalence of food fraud has also renewed interest in consumer studies. For example, studies on attitudes and perceptions towards food fraud and consumers' confidence in the food industry have been conducted in Bangladesh (Nasreen and Ahmed, 2014), China (El Benni et al., 2019; Kendall et al., 2018a, b), the UK and EU (Barnett et al., 2016; Charlebois et al., 2016; Van Rijswijk and Frewer, 2012) and Brazil (Breitenbach et al., 2018).

Conventional risk assessments are based on known criteria: the hazard (agent that can cause harm or substitution); the severity (degree of harm including financial or economic penalty) of the hazard if it occurs; and the likelihood (frequency) of the hazard to occur. Traditionally, food contaminants (biological, chemical and physical agents that can cause harm), food allergens and food quality issues are assessed independently but there is a need to consider risks in a more holistic approach (Manning and Soon, 2016). In addition, food safety management systems are developed to manage traditional food safety hazards and are not specifically designed for food fraud prevention and control (van Ruth et al., 2017). However, there has been a move to incorporate risk assessments or food fraud vulnerability assessments within third-party industry food safety and quality standards (e.g. Global Standard for food safety, version 8, BRC 2018), requiring the food industry to identify 
weaknesses and/or criticalities within their processing facilities or supply chains. Fraud vulnerability is a weakness or flaw in the system that creates opportunities for fraudsters to take advantage of. It is defined by three key fraud drivers i.e. opportunities, motivations and control measures (Spink, Ortega, Chen, \& Wu, 2017; van Ruth et al., 2017).

A number of risk assessments centred around fraud and food integrity issues have been developed in recent years. Table 1 shows the various definitions of food fraud and defence. Campden Threat Assessment and Critical Control Point (TACCP) is defined by PAS 96:2017 as the 'systematic management of risk through the evaluation of threats, identification of vulnerabilities and implementation of controls of the entire production process'. The threats controlled by TACCP include economically motivated adulteration (EMA) and malicious contamination, extortion, espionage, counterfeiting and cybercrime. TACCP is focused on identifying specific threats of criminal and malicious activity that can impact food safety (Campden BRI, 2019; Swainson, 2019). It follows the principles of Hazard Analysis and Critical Control Point (HACCP) and requires users to assemble a TACCP team, define the scope of study, review current TACCP measures, threat characterisation, mitigation strategy development, horizon scanning for new or emerging threats, implementation, recording and documentation and audit / review (Campden BRI, 2019). Questions and considerations in TACCP are detailed for the product, premises and the business including personnel security, controlling access to premises, services, processes and materials and secure storage of transport vehicles (Campden BRI, 2019).

Vulnerability Assessment and Critical Control Point (VACCP) is used in conjunction with TACCP. It is an inter-related process used to consider how vulnerable each point in the food process is to a particular criminal or malicious activity (Campden BRI, 2019; Swainson, 2019). However, according to GFSI (2017), TACCP and VACCP are defined separately. TACCP which evaluates threats is a 'process to ensure the security of food and drink from intentional malicious attack including ideologically motivated attack leading to contamination' (Table 1). Vulnerability is more of a state of being that could lead to an incident (Spink, 2014). VACCP focuses on susceptibility or exposure to food fraud. Its scope includes systematic prevention of potential adulteration of food - this could be intentional or not, via identification of vulnerable points in the supply chain (Global Food Safety Resource, 2019).

Insert Table 1 here 
In the United States of America, Spink et al. (2016) developed the Food Fraud Initial Screening Model (FFISM) where users can review previous incidents and suspicious activities, assess risks and prioritise their resources. Since FFISM is an initial screening tool, it allows for product groups with lower risks or established controls to be removed from subsequent vulnerability assessment, enabling companies to focus more specifically on higher risks. FFISM complements other assessment tool such as the Safe Supply of Affordable Food Everywhere (SSAFE). Its versatility and free accessibility allows users to assess vulnerabilities for different products, business size and region of operation (SSAFE, 2018).

It is noted that risk assessment continues to be the key step to identify food safety issues including fraud. The spice industry have tested vulnerability assessment tools such as the SSAFE, identifying the spice chain as being of medium vulnerability to food fraud (Silvis et al., 2017). The dairy sector too have utilised the SSAFE food fraud assessment tool and identified the Dutch milk supply chain as having low to medium vulnerability to fraud (Yang et al. in press). Van Ruth et al. (2018) assessed a number of other supply chains (fish, meat, dairy, olive oil and organic bananas) and found that opportunities and motivations to commit fraud remain key fraud drivers in the food supply chain. It is estimated that fraud costs the UK food economy $f 11$ billion a year but this is only the tip of the iceberg as fraud is massively underreported. By preventing fraud in food supply chain it is possible to reduce these estimated costs. In fact, by tackling fraud, this could boost the UK food industry's profit by $£ 4.5$ billion (Fraud Review Team, 2006; White 2017). However, to date, there is very little information regarding the number of reported frauds committed in the food industry or number of food industry / supply chain victimised by fraud. As fraud is not a policing priority this has resulted in substantial numbers of un-investigated cases (Doig, 2018). A culture within the food industry that questions the source of its supply chain and wider food integrity should be encouraged. A growing body of research has already focused on the detection of adulterated food products, analytical techniques and identifying vulnerable points in the food supply chain. What is not clear is the extent and usage of food fraud vulnerability assessments in the food supply chain. What type of assessment tools have been adopted by the food industry to mitigate food fraud? What actions are taken following such assessments? Thus, the purpose of this study is to investigate the use of food fraud vulnerability assessment tools and subsequent actions taken by the food industry.

\section{Methodology}

\section{Questionnaire Development}


The research utilised an online survey questionnaire, which was made available via SurveyMonkey ${ }^{\circledR}$.

140 Questions were developed from the current literature (Barnett et al., 2016; DEFRA, 2015; Menozzi et al. 2015; Rhodes, 2016) with the questionnaire being divided into six sections; (i) demographic characteristics; (ii) level of understanding of risk of food fraud; (iii) food fraud vulnerability assessments and tools used; (iv) actions taken following assessments; and (v) training. A pilot study among food fraud researchers and two food manufacturers was conducted to ensure the clarity and validity of the questionnaire and evaluate the time required to complete it.

\section{Participant Recruitment}

148 Food manufacturing companies were invited to participate in the study via email and calls for participation through a number of industry networks including the Food Integrity Intelligence Network (FIIN), the Federation of Bakers and the Food and Drink Federation between May and August 2017. The first and second authors also visited exhibition booths at Food Ingredients Europe (FIE) and Food and Drink Expo in November 2017 and April 2018 respectively, to garner further participation. A total of 23 food companies responded to these approaches and nineteen food manufacturers returned completed surveys.

\section{Results and Discussion}

The survey participants represented a wide cross-section of manufacturers within the food and drink industry. As shown in Table 2, 36.8\% of the manufacturers represented small and medium sized independent food business (companies operating with less than 50 employees), 26.3\% represented medium sized firms with 50-249 employees). Whilst all of the main product categories were represented in the survey (meat and fish; dairy and egg; fruits, vegetables and nuts; alcoholic drinks, bakery; ready meals and sandwiches; dried foods and ingredients), $31.6 \%$ of the study population classified their products as 'others', which encompassed a mixture of raw and cooked products, wet and dehydrated culinary products, marinades, meals for catering services, and honey.

About $1 / 3$ of the manufacturers reported that their food businesses had been victims of food fraud. Nine of the manufacturers (just under half of those surveyed) had experience of dealing with external fraud, i.e. where a business is a victim of fraud perpetrated by an external third party (e.g. by supply of inferior, substituted or adulterated foods, theft etc.), whilst six food businesses

170 (approximately $1 / 3$ ) reported experiences in dealing with internal food fraud. Internal fraud occurs at the place of employment, either as an individual acting alone or in collaboration with the modus operandi of the organisation. Internal staff have more access to processing facilities compared to 
external staff and as they understand the controls and preventive measures in place, may be able to work around them falsifying documentation if necessary (Manning and Soon, 2016). It is most likely that the external fraud occurred at the suppliers, sector or wider chain level and were detected before the manufacturing companies themselves became direct victims of fraud. This fits with previous research, as Van Ruth et al. (2017) reported that food frauds may originate from both the external or internal environment of a business. The findings however do not indicate if internal fraud is more easilycommitted compared to external fraud. It is possible that external frauds were identified and reported more frequently due to less stringent control and preventive measures (Manning, 2016), increased awareness of food fraud in the supply chain and / or perceived control over internal control measures. This is akin to an 'It won't happen to us' answer when people are questioned about the likelihood of being affected by harm or food fraud in this case (da Cunha, Stedefeldt, \& de Rosso, 2014; Weinstein, 1984).

Over $40 \%$ of the manufacturers stated that their businesses have designated staff who could advise on preventative and counter-fraud strategies, however, it is not known if these individuals are trained counter-fraud specialists. Whilst fraud analysts and investigators are often employed in banking, benefits, property claims and financial organisations, there are few reports of specialised counter-fraud staff being employed within the food industry. Within the enforcement community there have been moves to establish specialist teams to address food fraud and food crime. For example, the Danish Veterinary and Food Agency (DVFA) employs a "Food Fraud Flying Squad"; the Food and Consumer Products Safety Authority in the Netherlands have established an Intelligence and Investigation Service (IOD), and in the UK the National Food Crime Unit (NFCU) has been established within the Food Standards Agency (FSA) in the aftermath of the horsemeat scandal. All three agencies employ experts in criminal investigations, alongside individuals with the traditional scientific expertise (veterinary science, microbiology, food science etc.) associated with these agencies, with the aim of enabling comprehensive investigations into suspected food crime and food fraud (Evershed and Temple, 2016; NVWA-IOD, 2018). In fact, the NFCU are boosting their staff number from 22 to 80 to enhance their capabilities in addressing complex food crime (FSA, n.d.; Ridler, 2018).

More than half of the businesses surveyed also have a specific policy on fraud prevention, investigation and reporting in place. Such policies can serve as a beneficial guide for companies should fraud occur as well as enabling users to take preventative actions. 
As shown in Table 3, more than half of the businesses surveyed report using bespoke in-house tools for food fraud assessment. Based on their responses, these tools were adapted from United States Pharmacopeia (USP) and Campden TACCP guidelines. One organisation developed their own model in line with the National Intelligence model whilst considering their historical data, information from external sources and experts. Another, a cooked meat and fish products manufacturing company, designed their system based on their own experience and advice from industry experts, as well as utilising information from the FSA and UK Department for Environment Food and Rural Affairs (DEFRA) websites. Slightly more than a quarter of the food businesses surveyed adopted the Campden TACCP guidelines (which evaluates threats from food fraud and malicious contamination) directly, whilst two companies used the SSAFE tool. No organisations reported using USP or FFISM in their original formats. This may be because the companies surveyed are UK-based and so lack exposure to the tools developed in the U.S. It is also possible that tools from different countries collate historical fraud incidents related to the region and so best cater to the needs of the local food industry. Some of the manufacturers reported using analytical authenticity tests as a form of inhouse assessment tool. For example, a honey processing company utilised a Unique Manuka Factor (UMF) grading system, whilst a dairy and liquid egg company utilised isotope spectrometer analysis. GFSI assessments of both food defence and food fraud are carried out separately unlike Campden TACCP which can assess both criminal activity from fraud and malicious attack.

Insert Table 3 here

The main sources of information used by the food industry to support food fraud assessments were their own internal experts, guidelines provided by the different assessment methods, food safety certification bodies and professional memberships. Professional memberships such as the Federation of Bakers, Food and Drink Federation, Institute of Food Science and Technology, Institute of Food Technologists and the International Association for Food Protection provide networking opportunities and updates to members. Networking is one of the key information and knowledge sharing strategies employed by the food industry, especially in the area of open innovation (OI) (Bigliardi and Galati, 2013). Similarly, the food industry can create and share intelligence of food fraud incidents and mitigation strategies using these networks. For example, ESA (2018) and van Ruth et al. (2017) reported that companies that participated in European Spice Association meetings were warned about fraud and received an "adulteration awareness document". Desouza et al. 
241 (2005) found that organisations that do not utilise external knowledge are unable to compete in the marketplace in an effective way. Other sources of information include Food Industry Intelligence Network (FIIN), HorizonScan, suppliers and customers. Suppliers may be valuable sources of information as they have specific knowledge of the product and there is the opportunity for reciprocity in knowledge sharing between suppliers and buyers which can benefit both parties. (Török et al., in press). Similarly, customers too can potentially provide information about fraud incidents that have occurred. Information and knowledge sharing, together with collaborations with other actors in the supply chain, may be effective ways to reduce vulnerability to food fraud.

The majority of the companies in the survey carry out food fraud assessment training i.e. how to assess fraud vulnerability specific to their products and processes $(79 \%)$ and internal control measures (63\%). Control measures are actions taken to minimise, reduce or eliminate potential hazards from occurring (Wallace et al., 2011). Although the use of control measures to minimise and where possible eliminate the likelihood of unintentional food safety incidents is well established through the use of HACCP and pre-requisite programmes, the consideration of food fraud (i.e. intentional acts committed for financial gain) does not sit within the scope of traditional HACCPbased food safety management systems. Therefore, food businesses must consider additional internal control measures to minimise the likelihood of food fraud. For example, control measures can be currently built into product and packaging design via information systems for traceability, Radio Frequency Identification Devices (RFID), codes, tamper evident seals, holograms and special inks (Manning et al., 2016; Spink et al. 2010). Furthermore, intelligent packaging devices i.e. sensors, indicators and radio frequency identification (RFID), are expanding in response to food fraud, counterfeit, theft, diversion, safety, quality and reuse / recycling (Vanderroost et al., 2017a; Vanderoost et al., 2017b). Other control measures specific to fraud include whistleblowing guidelines (Soon and Manning, 2017), contractual requirements for suppliers (van Ruth et al. 2017), employee integrity screening and ethical codes of conduct (PWC, 2016). Capacity building in laboratory and analytical testing method remains crucial to ensure staff are competent and kept updated with current methods.

Interestingly, a small number of the surveyed food businesses had staff trained in forensic accounting. According to Power (2013) and Gee et al. (2014), forensic accounting has been adopted as a countermeasure to fraud to fight the practice of "false" suppliers as well as fraudulent practices by internal company staff (e.g. approval of false invoices, falsification delivery notes). Other flags for fraud that can be identified by forensic audit include false traceability documentation, missing paperwork, prices below commodity price, several similar purchases made below an authorisation 
level, high volumes of purchases from new vendors and excessive cash receipts/payments. The "Red Flags of Food Fraud" set out in the Elliott Review indicate the use of observation skills and forensic accounting techniques to reduce fraud vulnerability (Jack, in Elliott Review, 2014). Traceability tests and second party audits will also provide more information for focused forensic accounting. Indeed, it was a recommendation of the Elliott Review (2014) that the UK government should "support the work of standards' owners in developing additional audit modules for food fraud prevention and detection incorporating forensic accountancy and mass balance checks."

The food businesses were also questioned on their actions if their suppliers are suspected of perpetrating fraud. More than half would choose to delist their suppliers in combination with other methods including thorough investigation and supplier audits. Delisting an offending supplier may have a negative impact on production (e.g. the availability of ingredients) and the action is also dependent on whether the suppliers were directly involved in the fraud or were victims themselves. If suppliers have been victims of fraud due to lack of appropriate control measures in place, the manufacturers are willing to work with them to eliminate and/or reduce fraud vulnerability (Table 4). The findings from this study revealed that the decision to delist suppliers was also dependent on frequency of fraud i.e. if the issue occurred more than once.

Insert Table 4 here

A large proportion of the participating companies have had no non-conformances raised in external audits against food fraud vulnerability clauses. The four companies that reported non-conformances had either used their own fraud assessment tools or the SSAFE tool. This does not mean that other tools are better in assessing vulnerability points. One must bear in mind that different tools provide different functionality and is up to the company to adapt the tool accordingly i.e. adapt to own product or sector, process and region. BRC Global Standard for Food Safety Issue 8 requires food manufacturers to carry out a documented vulnerability assessment on food raw materials to assess potential risk of adulteration or substitution (BRC Global Standards, 2018) but the methodology of assessment is up to the manufacturers. The key challenge with food fraud vulnerability assessment is inconsistency, as multiple tools could be used, and the scope of assessments may vary (Whitworth, 2015) hence there is the risk of under or over predicting vulnerability points within the assessment tools. 
Food companies also reported utilising a number of strategies following food fraud risk assessment (qualitative responses to an open-ended question on 'What actions are taken by your company following food fraud risk assessment?'). These include routine surveillance analysis, supplier checks, site visits, traceability checks and specific full-on investigation in the case of known or suspected food fraud. In fact, one of the companies successfully recalled two containers of adulterated products en-route to their client and tightened their sourcing security and internal audits with their suppliers. Another company suggested that end consumers (i.e. public shoppers) must be educated as customers are the key drivers of safe and integrity products in the food supply chain.

The respondents were divided in terms of whether food fraud vulnerability assessments have a positive or negative impact on food fraud (Table 4). Those who perceived that the tools have a positive impact related this to putting an increased focus on an area that was not always considered properly, raising general awareness and ensuring that customers are getting what is labelled. The tools are believed to serve as an ongoing deterrent and preventative measure.

However, across the surveyed companies, there is still a level of uncertainty in terms of the impact of the tools. In response to the question: 'In your opinion, have food fraud vulnerability assessments had a positive / negative impact on food fraud?' one user was uncertain about the impact from such assessment tool and commented on the questions used in fraud assessment tool:

$$
\begin{aligned}
& \text { 'Why should we ask if the organisation owner is a celebrity? Assessments are very } \\
& \text { subjective. Unfortunately, a box ticking exercise by staff who are unaware of suppliers' } \\
& \text { reliability and how trustworthy they are, will be useless'. }
\end{aligned}
$$

Threat assessments for an organisation requires one to determine if the organisation has a celebrity or high-profile chief executive or proprietor (PAS 96:2017). This assessment allows one to assess for likelihood of threats and/or level of vulnerability to deliberate contamination of food by malicious or begrudged perpetrators against the owner. It is crucial that users understand why such assessments are required.

Two of the surveyed food businesses perceived a negative impact from the assessments, as they incur additional costs and may provide a bad image to the brand.

Insert Table 5 here 
343 In general the surveyed food businesses agreed that food fraud vulnerability assessments can help 344 to ensure food integrity, deter potential fraud risk and create an anti-fraud culture (Table 5). Food chain integrity covers all aspects of food chain from producers to consumers and encompasses microbial and chemical food safety, authenticity, fraud and quality (Hoorfar et al., 2011). Food manufacturers are one of the key actors in the chain and with appropriate control measures such as use of food fraud vulnerability assessment, can reduce opportunity for fraud. According to van Ruth et al. (2017), food fraud vulnerability is dependent on opportunities to commit fraud, motivations of fraudsters and control measures in place, whilst Moyer et al. (2017) suggest that fraudsters are unlikely to engage in illegal activity if they perceive the chance of being caught high Conducting assessments allows users to identify points of vulnerability, review their control measures and as a result of the ongoing assessment, this can help to reduce and/or deter fraud opportunities and demotivate fraudsters from taking action. Establishing the correct ethical standards, creating appropriate management support and environment for food businesses are also an important part of creating an anti-fraud culture. A strong ethical standards culture will encourage employees to adhere to the organisations' rules and regulations (Rae and Subramaniam, 2008) and limits the risk of unethical behaviour (van Ruth et al., 2017). People are governed by the culture and environment in which they operate. In fact, an unethical business culture that encourages law breaking in the pursuit of profit can "normalize" fraud and reinforce longer-term fraudulent activity (Coleman, 1987; Raftery and Holder, 2014).

The respondents mostly agreed that they have stronger internal controls (e.g. control measures within organisation; own staff) compared to external controls (e.g. third party audits; inspections) over the application of food fraud vulnerability assessment. They believed that their own staff will be able to carry out the assessment and the control measures within their facilities can prevent food fraud. Meanwhile, there was more uncertainty about government and external inspectors' role in preventing food fraud. Previous research has revealed diminished public confidence in the government and food industry following the horsemeat incident (Barnett et al., 2016; Elliott Review, 2014; Premanandh, 2013; Tse et al., 2016). Consumers were found to be less tolerant of uncertainty due to lack of action or lack of interest from the government (Frewer et al., 2002). Although internal control measures are crucial, regulatory controls are necessary to enforce food safety regulations

373 (FSA, 2018a). Some studies have demonstrated that regulatory control and official inspections help 374 to reduce food fraud (Liu, 2016; Nasreen and Ahmed 2014). The UK FSA is modernising the way food businesses are regulated under the 'Regulating our Future' (ROF) programme (FSA, 2018b). A new 
402

risk management approach will be introduced where food businesses doing the right thing will be recognised but action will be taken against those that do not. The ROF programme is timely as it needs to address the changing nature of the food industry (e.g. rise in online retailers, food delivery services, private auditors), constrained enforcement resources and environmental changes with preparations to leave the European Union (FSA, 2017).

There is also strong agreement to continue with the current food fraud risk assessment model and the food businesses agreed that they will search for more information to support the assessment. For example, information developed by the British Standards Institution such as the PAS 2017 Guide to protecting and defending food and drink from deliberate attack (FSA, 2018c; PAS 96: 2017) can be used by food businesses to assess potential vulnerabilities to fraud.

\section{Limitations and future research}

The small sample size and low response rate from the food industry are major limitations in the study. Despite assurances of anonymity and confidentiality businesses appear reluctant to communicate their actions - or lack of them - in tackling this sensitive issue. There is also a possibility of social desirability bias in the responses received, as manufacturers may want to project an optimistic perspective of their activities. Further insight could be obtained through interviews with individual food companies to explore the benefits and challenges in using the current food fraud vulnerability assessment tools. Future research should also explore why companies prefer to use in-house models and whether there is a restriction in terms of time, expertise and capital to subscribe to online food fraud vulnerability assessment tools? It is also worth exploring in-depth the companies that have been victims of internal and/or external fraud. Van Ruth et al. (2017) indicated that companies who have been victims of fraud are more likely to become indirectly involved in future frauds again. In fact, repeat victimization could occur if vulnerabilities were not mitigated after the first event.

\section{Conclusion}

In house food fraud vulnerability assessments were the preferred models of assessment among the surveyed food businesses. Around one third of the companies had been victims of food fraud, although about half of the companies have had experience in dealing with external food fraud. Food manufacturers were divided about the impact of conducting food fraud vulnerability assessments. Although such assessments are believed to help to raise awareness and ensure the integrity of the food supply chain, some food businesses are still uncertain about the impact of food fraud 
vulnerability assessments, with concerns raised about cost and brand reputation. Since the adoption and conduct of the vulnerability assessments is fairly new, it is inevitable that the full impact remains to be seen. With time and ongoing vigilance from the food industry, food fraud vulnerability assessments will benefit the sector and ensure the safety and integrity of the food supply chain. Looking beyond the scope of the current study, future research could investigate the relation between demographic characteristics, experience in dealing with fraud, cultural differences and their food fraud vulnerability assessment strategies. Longitudinal studies with food manufacturers to assess the impact of such assessments will quantify the extent and type of impacts e.g. food safety, public health, finance and brand reputation.

\section{Acknowledgements}

The authors would like to thank all participating food manufacturers. The authors gratefully acknowledge the Food Integrity Intelligence Network (FIIN) and Federation of Bakers for advertising the survey among their members and to Food Ingredients Europe (FIE) and Food and Drink Expo conference exhibitors for their time.

\section{References}

Abbas, O., Zadravec, M., Baeten, V., Mikus, T., Lesic, T., Vuliv, A. et al. (2018). Analytical methods used for the authentication of food of animal origin. Food Chemistry, 246, 6-17.

Barnett, J., Begen. F., Howes, S., Regan, A., McConnon, A., Marcu, A., Rowntree, S. and Verbeke, W. (2016). Consumers' confidence, reflections and response strategies following the horsemeat incident. Food Control, 59(1), 721-730.

Bigliardi, B. and Galati, F. (2013). Models of adoption of open innovation within the food industry. Trends in Food Science \& Technology, 30(1), 16-26.

BRC Global Standards (2018). Food safety. Available at: https://www.brcglobalstandards.com/brc-globalstandards/food-safety/ [Accessed 19 August 2018]

Breitenbach, R., Rodrigues, H. and Brandao, J. B. (2018). Whose fault is it? Fraud scandal in the milk industry and its impact on product image and consumption - The case of Brazil. Food Research International, 108, 475-481.

BRC Global Standards. (2018). BRC Global Standard Food Safety Version 8 (August 2018). London: BRC Global Standards.

Campden BRI (2014). TACCP: New guidance from Campden BRI. Available at: https://www.campdenbri.co.uk/pr/aug18.pdf [Accessed 19 August 2018]

Campden BRI (2019). TACCP/VACCP Threat and vulnerability assessments: a practical guide. Guideline 72. Second edition. Campden BRI. 

measuring consumer perception towards mislabeled food products and influence on selfauthentication intentions. Trends in Food Science \& Technology, 50, 211-218.

Coleman, J. W. (1987). Toward an integrated theory of white-collar crime. American Journal of

Da Cunha, D. T., Stedefeldt, E., \& de Rosso, V. V. (2014). He is worse than I am: The positive outlook of food handlers about foodborne disease. Food Quality and Preference, 35, 95-97.

DEFRA (2015). Food statistics pocketbook 2015. Available at:

https://www.gov.uk/government/uploads/system/uploads/attachment_data/file/526395/foodpock etbook-2015update-26may16.pdf [Accessed 28 Jan 2017]

Desouza, K. C., Awazu, Y., and Jasimuddin, S. (2005). Utilizing external sources of knowledge. KM Review, 8(1), 16-19.

Doig, A. (2018). Fraud: from national strategies to practice on the ground - a regional case study. Public Money \& Management 38(2), 147-156.

EC (2018). Monthly summary of articles on food fraud and adulteration. January 2018. Available at: https://ec.europa.eu/jrc/sites/jrcsh/files/jrc-food-fraud-summary-january-2018.pdf [Accessed 25 August 2018]

El Benni, N., Stolz, H., Home, R., Kendall, H., Kuznesof, S., Clark, B., Dean, M., Brereton, P., Frewer, L. J., Chan, M.-Y., Zhong, Q. and Stolze, M. (2019). Product attributes and consumer attitudes affecting the preferences for infant milk formula in China - A latent class approach. Food Quality and Preference, 71, 25-33.

Elliott Review (2014). Elliott review into the integrity and assurance of food supply networks - Final report. A national food crime prevention framework. HM Government, July 2014 London.

ESA, European Spice Association (2018). European Spice Association Quality Minima Document. Available at: https://www.esa-spices.org/download/esa-qmd-rev-5-update-as-per-esa-tc-26-03-18.pdf [Accessed 1 September 2018]

Esteki, M., Shahsavari, Z. and Simal-Gandara, J. (2018). Use of spectroscopic methods in combination with linear discriminant analysis for authentication of food products. Food Control, 91, 100-112.

Evershed, R. and Temple, N. (2016). Sorting the beef from the bull. The science of food fraud forensics. London: Bloomsbury Sigma, pp. 1-320.

Everstine, K., Spink, J. and Kennedy, S. (2013). Economically motivated adulteration (EMA) of food: Common characteristics of EMA incidents. Journal of Food Protection, 76(4), 723-735.

Food Fraud Risk Information (2018). Recent food fraud incidents - August 2018. Available at: https://trello.com/b/aoFO1UEf/food-fraud-risk-information [Accessed 25 August 2018] Fraud Review Team (2006). Fraud review final report. Available at: http://webarchive.nationalarchives.gov.uk/20070222120000/http://www.Islo.gov.uk/pdf/FraudRevi ew.pdf [Accessed 8 January 2019] 
503

504

505

506

507

508

509

510

511

512

513

514

515

516

517

518

519

520

521

522

523

524

525

526

527

528

529

530

531

532

533

534

535

536

537

538

539

540

541

542

543

544

545

546

547

548

549

550

551

552

553
Frewer, L., Miles, S., Brennan, M., Kuznesof, S., Ness, M. and Ritson, C. (2002). Public preferences for informed choice under conditions of risk uncertainty. Public Understanding of Science, 11(4). 363372.

FSA, Food Standards Agency (n.d.). Working for us. Available at: https://www.food.gov.uk/aboutus/working-for-us [Accessed 29 August 2018]

Gee, J., Jack, L. and Button, M. (2014). Minimising fraud and maximising value in the UK food and drink sector. Available at: https://core.ac.uk/download/pdf/52402535.pdf [Accessed 31 August 2018]

GFSI, Global Food Safety Initiative (2017). GFSI benchmarking requirements version 7.2. Available from: https://www.mygfsi.com/certification/benchmarking/gfsi-guidance-document.html [Accessed 26 February 2019]

Global Food Safety Resource (2019). TACCP and VACCP: What's the difference? Available at: https://globalfoodsafetyresource.com/taccp-and-vaccp-what-is-the-difference/ [Accessed 8 January 2010]

Grace, D. (2019). Food fraud. Reference Module in Food Science. Encyclopedia of Food Security and Sustainability, Vol. 1, 238-248.

Hoorfar, J., Pruggerl, R., Butler, F and Jordan. K. N. (2011). Future trends in food chain integrity. In, Food Chain Integrity. A holistic approach to food traceability, safety, quality and authenticity.

Cambridge: Woodhead Publishing, pp. 303-308.

Jack, L. (2014) The Red Flags of Food Fraud in Elliott Review. Elliott review into the integrity and assurance of food supply networks - Final report. A national food crime prevention framework. HM Government, July 2014 London, pp. 114-116.

Kendall, H., Kuznesof, S., Dean, M., Chan, M.-Y., Clark, B., Home, R., Stolz, H., Zhong, Q., Liu, C., Brereton, P. and Frewer, L. (2018a). Chinese consumer's attitudes, perceptions and behavioural responses towards food fraud. Food Control, doi: doi.org/10.1016/j.foodcont.2018.08.006

Kendall, H., Naughton, P., Kuznesof, S., Raley, M., Dean, M., Clark, B., Stolz, H. et al. (2018b). Food fraud and the perceived integrity of European food imports into China. Plos ONE, 13(5), E0195817.

Leathers, R. (2018). BRC Global Standard for Food Safety Issue 8: a guide to key changes. Available at: https://www.campdenbri.co.uk/blogs/brc-8-key-changes.php [Accessed 26 February 2019]

Liu, C.-Y. (2016). Institutional isomorphism and food fraud: A longitudinal study of mislabelling rice in Taiwan. Journal of Agricultural and Environmental Ethics, 29(4), 607-630.

Manning, L. (2016). Food fraud: policy and food chain. Current Opinion in Food Science, 10, 16-21.

Manning, L., Smith, R., \& Soon, J.M (2016). Developing an Organizational Typology of Criminals in the Meat Supply Chain, Food Policy, 59, pp. 44-54

Manning, L. and Soon, J. M. (2016). Food safety, food fraud, and food defense: A fast evolving literature. Journal of Food Science, 81(4), R823-R834. 
Menozzi, D., Halawany-Darsonm R., Mora, C. and Giraud, G. (2015). Motives towards traceable food choice: A comparison between French and Italian consumers. Food Control 49: 40-48.

Mutuko, M. (2018). 1 million bags of poisonous rice nabbed. Available at: https://www.kenyans.co.ke/news/32527-1-million-bags-poisonous-rice-nabbed [Accessed 25 August 2018].

Nasreen, S. and Ahmed, T. (2014). Food adulteration and consumer awareness in Dhaka City, 19952011. Journal of Health, Population and Nutrition, 32(3), 452-464.

NVWA (Netherlands Food and Consumer Product Safety Authority) (2018). Dutch authorities (NVWA-IOD) arrest 2 men in fipronil case. Available at:

https://english.nvwa.nl/news/news/2017/08/10/dutch-authorities-nvwa-iod-arrest-two-men-infipronil-case [Accessed 4 October 2018]

Pardo, M. A., Jimenez, E., Vioarsson. J. R., Olafsson. K., Olafsdottir,G., Danielsdottir, A. K. and PerezVillareal, B. (2018). DNA barcoding revealing mislabelling of seafood in European mass caterings. Food Control, 92, 7-16.

PAS 96 (2017). Guide to protecting and defending food and drink from deliberate attack. Available at: https://www.food.gov.uk/sites/default/files/pas962017.pdf [Accessed on 26 February 2019].

Power, M. (2013). The apparatus of fraud risk. Accounting, Organizations and Society, 38, 525-543.

Premanandh, J. (2013). Horse meat scandal - A wake-up call for regulatory authorities. Food Control, 34(2), 568-569.

PWC (2016). Food fraud vulnerability assessment and mitigation: Are you doing enough to prevent food fraud? Available at: https://www.pwc.com/gx/en/services/food-supply-integrityservices/assets/pwc-food-fraud-vulnerability-assessment-and-mitigation-november.pdf [Accessed 1 September 2018]

Rae, K. and Subramanian, N. (2008). Quality of internal control procedures: Antecedents and moderating effect on organisational justice and employee fraud. Managerial Auditing Journal, 23(2), 104-124.

Raftery, H. and Holder, F. L. (2014). Business fraud: Culture is the culprit. FTI Journal. Available at: http://ftijournal.com/article/business-fraud-culture-is-the-culprit [Accessed 1 September 2018]

Ridler, J. (2018). Collaboration needed to tackle food fraud. Food Manufacture UK. Available at: https://www.foodmanufacture.co.uk/Article/2018/06/26/Food-supply-chain-needs-to-collaborateto-prevent-fraud [Accessed 29 August 2018]

Rhodes, C. (2016). Business statistics. Briefing paper Number 06152, 23 November. Available at: http://researchbriefings.files. parliament.uk/documents/SN01652/SN01652.pdf [Accessed 29 January 2017]

Silvis, I. C. J., van Ruth, S. M., van der Fels-Klerx, H. J. and Luning, P. A. (2017). Assessment of food fraud vulnerability in the spices chain: An explorative study. Food Control, 81, 80-87. 
Soon, J. M. and Manning, L. (2017). Whistleblowing as a countermeasure strategy against food crime. British Food Journal, 119(12), 2630-2652.

Spink, J. (2014). GFSI direction on food fraud and vulnerability assessment (VACCP). Food Fraud Initiative. Available at: http://foodfraud.msu.edu/2014/05/08/gfsi-direction-on-food-fraud-andvulnerability-assessment-vaccp/ [Accessed 8 January 2019]

Spink, J., Helferich, O. K., \& Griggs, J. E. (2010). Combating the impact of product counterfeiting. Distribution Business Management Journal, 10, 59-63.

Spink, J. and Moyer, D. (2011). Defining the public health threat of food fraud. Journal of Food Science, 76(9), R157-R163.

Spink, J., Moyer, D. C. and Speier-Pero, C. (2016). Introducing the Food Fraud Initial Screening model (FFIS). Food Control, 69, 306-314.

Spink, J., Ortega, D. L., Chen, C. and Wu. F. (2017). Food fraud prevention shifts the food risk focus to vulnerability. Trends in Food Science \& Technology, 62, 215-220.

SSAFE (2018). SSAFE food fraud vulnerability assessment tool. Available at: http://www.ssafefood.org/ [Accessed 26 August 2018]

Swainson, M. (2019). Food sector challenges and the role of technical and quality management. In, Swainson's Handbook of Technical and Quality Management for the Food Manufacturing Sector. Cambridge: Woodhead Publishing, pp. 1-606.

Török, Á. , Tóth, J. and Balogh, J. M. (in press). Push or pull? The nature of innovation process in the Hungarian food SMEs. Journal of Innovation \& Knowledge, doi.org/10.1016/j.jik.2018.03.007

Tse, Y. K., Zhang, M., Doherty, B., Chappell, P. and Garnett, P. (2016). Insight from the horsemeat scandal: Exploring the consumers' opinion of tweets toward Tesco. Industrial Management \& Data Systems, 116(6). 1178-1200.

US FDA (2018). Mitigation strategies to protect food against intentional adulteration: Guidance for industry. Available at:

https://www.fda.gov/downloads/Food/GuidanceRegulation/GuidanceDocumentsRegulatorylnforma tion/UCM611043.pdf [Accessed 26 February 2019]

Valdes, A., Beltran, A., Mellinas, C., Jimenez, A. and Garrigos, M .C. (2018). Analytical methods combined with multivariate analysis for authentication of animal and vegetable food products with high fat content. Trends in Food Science \& Technology, 77, 120-130.

Vanderroost, M., Ragaert, P., Verwaeren, J., De Meulenaer, B., De Baets, B., \& Devlieghere, F. (2017a). The digitization of a food package's life cycle: Existing and emerging computer systems in the logistics and post-logistics phase. Computers in Industry, 87, 15-30.

Vanderroost, M., Ragaert, P., Devlieghere, F., \& De Meulenaer, B., (2017b). Intelligent food packaging: The next generation. Trends in Food Science \& Technology, 39, 47-62.

Van Rijswijk, W. and Frewer, L. J. (2011). Consumer needs and requirements for food and ingredient traceability information. International Journal of Consumer Studies, 36(3), 282-290. 
van Ruth, S. M., Huisman, W. and Luning, P. A. (2017). Food fraud vulnerability and its key factors. Trends in Food Science \& Technology, 67, 70-75.

659

van Ruth, S. M., Luning, P. A., Silvis, I. C.J., Yang, Y. and Huisman, W. (2018). Differences in fraud vulnerability in various food supply chains and their tiers. Food Control, 84, 375-381.

Wallace, S., Sperber, W. H. and Mortimore, S. (2011). Food safety for the $21^{\text {st }}$ century: Managing HACCP and food safey throughout the global supply chain. Chichester: Wiley-Blackwell, pp. 1-315.

Weinstein, N. D. (1984). Why it won't happen to me: Perceptions of risk factors and susceptibility. Health Psychology, 3(5), 431-457.

White, V. (2017). Food fraud: a challenge for the food and drink industry. New Food. Available at: https://www.newfoodmagazine.com/article/22854/food-fraud-an-emerging-risk-for-the-food-anddrink-industry/ [Accessed 8 January 2019]

672

Whitworth, J. J. (2015). Cert ID warns against inconsistent vulnerability assessments. Available at: https://www.foodnavigator.com/Article/2015/08/04/Vulnerability-Assessments-one-big-change-in-

Xiong, X., Yao, L., Ying, X., Lu, L., Guardone, L., Armani, A., Guidi, A. and Xiong, X. (2018). Multiple fish species identified from China's roasted Xue Yu fillet products using DNA and mini-DNA barcoding: Implications on human health and marine sustainability. Food Control, 88, 123-130.

Yang, Y., Huisman, W., Hettinga, K. A., Liu, N., Heck, J., Schrijver, G. H., Gaiardoni, L. and van Ruth, S. $M$. (in press). Fraud vulnerability in the Dutch milk supply chain: Assessments of farmers, processors and retailers. Food Control, doi: doi.org/10.1016/j.foodcont.2018.08.019

Table 1. Food safety standards and definitions of food fraud and food defence

\begin{tabular}{llll}
\hline Standards & Food fraud & Food defence & Notes \\
\hline BRC Global Standard for & Documented & Potential for & Food processing sites \\
Food Safety (Issue 8, & vulnerability & deliberate malicious & are looking at \\
2018) & assessment shall be & contamination & combining the food \\
& carried out on all food & sources need to be & defence requirements \\
& raw materials to & risk assessed, & with the \\
& assess potential risk & managed and & requirements for \\
& of adulteration & reviewed (Clauses & Food Fraud as the \\
& (Clauses 5.4.1, 5.4.2, & $4.2 .1,4.2 .2$ and 4.2.3) & methodology and \\
& $5.4 .3)$ & & principles defined in \\
& & & TACCP guidance \\
& & & document \\
& & & PAS96:2017 are
\end{tabular}




\begin{tabular}{|c|c|c|c|}
\hline & & & $\begin{array}{l}\text { similar (Leathers, } \\
\text { 2018) }\end{array}$ \\
\hline GFSI (2017) & $\begin{array}{l}\text { Process to ensure the } \\
\text { security of food and } \\
\text { drink from all forms } \\
\text { of intentional } \\
\text { malicious attack } \\
\text { including ideologically } \\
\text { motivated attack } \\
\text { leading to } \\
\text { contamination }\end{array}$ & $\begin{array}{l}\text { Deliberate and } \\
\text { intentional } \\
\text { substitution, addition, } \\
\text { tampering or } \\
\text { misrepresentation of } \\
\text { food, food ingredients } \\
\text { or food packaging, } \\
\text { labelling, product } \\
\text { information or false } \\
\text { or misleading } \\
\text { statements made } \\
\text { about a product for } \\
\text { economic gain that } \\
\text { could impact } \\
\text { consumer health }\end{array}$ & $\begin{array}{l}\text { Essential to note that } \\
\text { GFSI defines food } \\
\text { fraud separately from } \\
\text { food defence }\end{array}$ \\
\hline PAS96:2017 & $\begin{array}{l}\text { Dishonest act or } \\
\text { omission, relating to } \\
\text { the production or } \\
\text { supply of food, which } \\
\text { is intended for } \\
\text { personal gain or to } \\
\text { cause loss to another } \\
\text { party }\end{array}$ & $\begin{array}{l}\text { Procedures adopted } \\
\text { to assure the security } \\
\text { of food and drink and } \\
\text { their supply chains } \\
\text { from malicious and } \\
\text { ideologically } \\
\text { motivated attack } \\
\text { leading to } \\
\text { contamination or } \\
\text { supply disruption }\end{array}$ & \\
\hline $\begin{array}{l}\text { Campden TACCP } \\
\text { (Campden BRI, 2019; } \\
\text { Swainson, 2019) }\end{array}$ & $\begin{array}{l}\text { Systematic manageme } \\
\text { evaluation of threats, } \\
\text { vulnerabilities and imp }\end{array}$ & $\begin{array}{l}\text { th of risk through the } \\
\text { lentification of } \\
\text { ementation of controls }\end{array}$ & $\begin{array}{l}\text { Note that Spink and } \\
\text { Moyer (2011) suggest } \\
\text { that food defence }\end{array}$ \\
\hline $\begin{array}{l}\text { Campden VACCP } \\
\text { (Campden BRI, 2019; } \\
\text { Swainson, 2019) }\end{array}$ & $\begin{array}{l}\text { Consider how vulnerab } \\
\text { supply chain is to that } \\
\text { criminal/malicious acti } \\
\text { related process with T/ }\end{array}$ & $\begin{array}{l}\text { e each point in the } \\
\text { hreat of } \\
\text { ity. VACCP is an inter- } \\
\text { CCP }\end{array}$ & $\begin{array}{l}\text { activities are distinct } \\
\text { from food fraud. Food } \\
\text { defence strategies are } \\
\text { efforts undertaken to }\end{array}$ \\
\hline
\end{tabular}


protect food from

intentional acts of

adulteration.

US FDA (2018)

Effort to protect food

from intentional acts

of adulteration where

there is an intent to

cause wide scale

public health harm

686

687

Table 2. Demographic characteristics of survey participants $(n=19)$

\begin{tabular}{|c|c|c|}
\hline Variable & Items & Frequency (\%) \\
\hline \multirow[t]{2}{*}{ Gender } & Male & $11(57.9)$ \\
\hline & Female & $8(42.1)$ \\
\hline \multirow[t]{5}{*}{ Age (years) } & $18-30$ & $2(10.5)$ \\
\hline & $31-40$ & $6(31.6)$ \\
\hline & $41-50$ & $3(15.8)$ \\
\hline & $51-60$ & $5(26.3)$ \\
\hline & $>60$ & $3(15.8)$ \\
\hline \multirow[t]{2}{*}{ Education } & Secondary & $3(15.8)$ \\
\hline & Tertiary & $16(84.2)$ \\
\hline \multirow[t]{9}{*}{ Food and drink manufacturing type } & $\begin{array}{l}\text { Raw fish products and } \\
\text { preparations }\end{array}$ & $1(5.3)$ \\
\hline & Fruit, vegetables and nuts & $1(5.3)$ \\
\hline & Dairy, liquid egg & $2(10.5)$ \\
\hline & $\begin{array}{l}\text { Cooked meat / fish } \\
\text { products }\end{array}$ & $1(5.3)$ \\
\hline & $\begin{array}{l}\text { Ready meals and } \\
\text { sandwiches }\end{array}$ & $1(5.3)$ \\
\hline & $\begin{array}{l}\text { Alcoholic drinks and } \\
\text { fermented brewed } \\
\text { products }\end{array}$ & $2(10.5)$ \\
\hline & Bakery & $2(10.5)$ \\
\hline & $\begin{array}{l}\text { Dried foods and } \\
\text { ingredients }\end{array}$ & $3(15.8)$ \\
\hline & Others & $6(31.6)$ \\
\hline \multirow[t]{4}{*}{ Number of employees } & $0-9$ & $4(21.1)$ \\
\hline & $10-49$ & $3(15.8)$ \\
\hline & $50-249$ & $5(26.3)$ \\
\hline & $250+$ employees & $7(36.8)$ \\
\hline
\end{tabular}




\begin{tabular}{|c|c|c|}
\hline \multirow[t]{2}{*}{ Independent / multinational company } & Independent & $13(68.4)$ \\
\hline & Multinational & $6(31.6)$ \\
\hline \multirow[t]{3}{*}{ Has the company been a victim of food fraud? } & Yes & $6(31.6)$ \\
\hline & No & 11 (57.9) \\
\hline & Uncertain & $2(10.5)$ \\
\hline \multirow{3}{*}{$\begin{array}{l}\text { I have experience dealing with internal food } \\
\text { fraud }\end{array}$} & Yes & $6(31.6)$ \\
\hline & No & $11(57.9)$ \\
\hline & Uncertain & $2(10.5)$ \\
\hline \multirow{3}{*}{$\begin{array}{l}\text { I have experience dealing with external food } \\
\text { fraud }\end{array}$} & Yes & $9(47.4)$ \\
\hline & No & $9(47.4)$ \\
\hline & Prefer not to say & $1(5.3)$ \\
\hline \multirow{3}{*}{$\begin{array}{l}\text { Does the company have a designated individual / } \\
\text { fraud officer to advice on fraud incidents? }\end{array}$} & Yes & $8(42.1)$ \\
\hline & No & $10(52.6)$ \\
\hline & Uncertain & $1(5.3)$ \\
\hline \multirow{3}{*}{$\begin{array}{l}\text { Does your company have a specific policy on } \\
\text { fraud prevention, investigation and reporting? }\end{array}$} & Yes & $10(52.6)$ \\
\hline & No & $7(36.8)$ \\
\hline & Uncertain & $2(10.5)$ \\
\hline
\end{tabular}

691 Table 3. Types of food fraud assessment tools, resources and training conducted in food businesseS

\begin{tabular}{lc}
\hline Items & Frequency (\%) \\
\hline Campden Threat and Critical Control Points & $5(26.3)$ \\
United States Pharmacopeia (USP) Food Fraud Mitigation & 0 \\
Safe Supply of Affordable Food Everywhere (SSAFE) Vulnerability & $2(10.5)$ \\
Assessment Tool & 0 \\
Food Fraud Initial Screening Tool & $7(36.8)$ \\
In-house assessment tool (e.g. own bespoke / adapted tools) & $5(26.3)$ \\
Others (e.g. product testing) & \\
& \\
*Sources of information used to support food fraud assessments & $9(47.4)$ \\
Guidelines provided by assessment method & $12(63.2)$ \\
Internal experts & $5(26.3)$ \\
External experts & $6(31.6)$ \\
Food safety certification bodies & $4(21.1)$ \\
Media & $2(10.5)$ \\
Food magazines & $1(5.3)$ \\
Peer-reviewed journal articles & $6(31.6)$
\end{tabular}


Academia

*Types of food fraud assessment training conducted in the company

Food fraud vulnerability assessment

Laboratory and analytical instrument training $\quad 10(52.6)$

Verification of supplier training

Internal control measures

Forensic accounting 2 (10.5)

Others

Note: * Participants can select more than one option

Table 4. Actions taken post vulnerability assessment or if suspicion of fraud arises

\begin{tabular}{lc}
\hline Items & Frequency (\%) \\
\hline What are your *action(s) if there is suspicion of fraud by your suppliers: & \\
Delist the supplier & $10(52.6)$ \\
Work with them to eliminate the problem & $7(36.8)$ \\
Others (e.g. investigation, supplier audits) & $8(42.1)$ \\
& \\
Any non-conformances raised in audits against food fraud vulnerability & \\
clauses / requirements? & $4(21.1)$ \\
Yes & $12(63.2)$ \\
No & $3(15.8)$ \\
Uncertain & \\
In your opinion, have food fraud vulnerability assessments had a positive / & \\
negative impact on food fraud? & \\
Positive & $9(47.4)$ \\
Negative & $2(10.5)$ \\
Uncertain & $8(42.1)$ \\
\hline
\end{tabular}

Note: *Food businesses can select more than one option

Table 5. Perceptions of food fraud vulnerability assessments (1 - Strongly disagree; 5 - Strongly agree)

\begin{tabular}{lcc}
\hline Food fraud vulnerability assessment is able to: & Mean & S.D. \\
\hline Trace origin of food & 3.47 & 1.26 \\
Verify vendor and supplier status & 3.68 & 1.16 \\
Ensure integrity of food & 4.11 & 0.99 \\
Result in safer food & 3.63 & 0.89 \\
Deter potential fraud risk & 3.89 & 0.94 \\
Detect existing fraud & 3.63 & 0.89 \\
Create anti-fraud culture & 3.74 & 0.81
\end{tabular}

\section{External control measures}


I feel confident that external staff / inspectors can prevent

fraud

Government emphasis on fraud prevention strategies can

prevent fraud

\section{Internal control measures}

I feel confident that our food fraud vulnerability assessment can

prevent fraud

I have internal control measures in place to prevent food fraud

I intend to:

Apply food fraud vulnerability assessment (if new)

N/A

N/A

Continue with my current food fraud vulnerability assessment

4.16

0.76

Search for more information regarding food fraud vulnerability

3.84

0.89 assessment 